\title{
¿PUEDE LA INVESTIGACIÓN JURÍDICA CONSIDERARSE CIENTÍFICAMENTE VÁLIDA? LA ARGUMENTACIÓN COMO CRITERIO DE VALIDEZ
}

\author{
¿Is Legal Research Truly Scientific? Legal Argumentation As Criteria Of Validity
}

Luis GoNZÁLEZ PLACENCIA *

Sumario:

I. Planteamiento del problema II. La investigación jurídica como una forma de investigación cualitativa III. La validez cientifica en la investigación cualitativa de los fenómenos jurídicos IV. Reflexiones conclusivas

Resumen: Asumiendo las críticas que con frecuencia recibe la investigación jurídica por la falta de atención a las cuestiones de método, el presente artículo plantea la necesidad de generar pautas que garanticen el rigor académico del trabajo jurídico y propone a la argumentación como su criterio de validez científica. Con base en Atienza, el texto sugiere el uso de la lógica proposicional, del modelo de argumentación de Toulmin, así como de las reglas del discurso que Alexy toma de Habermas, como elementos para la construcción de un modelo de evaluación de la investigación jurídica que le garantice rigor metódico y validez científica.

Palabras clave: Argumentación jurídica, Metodología de la investigación, Investigación jurídica, Enseñanza, Evaluación

Abstract: Assuming the critics that legal research often receives due to the lack of scientific grounds based in the method, this article raises the need to generate guidelines that guarantee the academic rigor of legal work and propose legal argumentation as its criteria of scientific validity. Based on Atienza, this text suggests the use of propositional logic, Toulmin's model of argumentation and the rules of practical speech that Alexy borrows from Habermas, as constitutive elements of a model for the evaluation of legal research aimed to guarantee methodical rigor and scientific validity.

Keywords: Legal Argumentation, Legal Research, Teaching, Research Methodology, Evaluation

* Profesor titular de metodología en el doctorado en Derecho y Argumentación Jurídica del Centro de Estudios Jurídicos y Políticos de la Universidad Autónoma de Tlaxcala y Coordinador General fundador del Posgrado Interinstitucional en Derechos Humanos de la misma institución. 


\section{Planteamiento del problema}

Uno de los problemas que con frecuencia se asocia a las disciplinas jurídicas tiene que ver con la ausencia de criterios como los que, en el campo de las ciencias naturales, garantizan el rigor científico del trabajo académico. No es raro leer que se cuestiona el estatus científico de la investigación jurídica o que se afirme que lo que las y los juristas producen se halla mucho más próximo a la ideología o la expresión de opiniones y puntos de vista, que al conocimiento controlado por el rigor metódico de la ciencia. Aunque sin duda existe trabajo académico de primer nivel en el terreno jurídico, mucho de cierto hay también en que las y los investigadores de los fenómenos jurídicos poca atención han puesto al tema del método y a que éste debería normar, con sus particularidades, no solamente la producción académica en los centros de investigación, sino, de hecho, constituir el contenido de una disciplina que ayudara a formar investigadores rigurosos ${ }^{1}$.

En efecto, la experiencia de muchos colegas que han dedicado parte de sus esfuerzos a la asesoría de tesis en maestrías y doctorados corrobora que es urgente tener acuerdos y dedicar algunas - muchas- horas a la construcción de un método que aplique a las formas y exigencias de la investigación jurídica y, otras tantas -muchas más-a la enseñanza de la metodología a lo largo de los ciclos de formación universitaria de pre y posgrado. Huelga decir que ello también contribuiría a establecer referentes más objetivos para normar la tan frecuentemente cuestionada labor de revisar el trabajo de pares, lo que supone exteriorizar y, en alguna medida, a hacer menos subjetivos, menos decisionistas, los criterios que se emplean en las evaluaciones que se realizan en instancias de promoción y reconocimiento académico, sean éstas intra institucionales, como los que se llevan a cabo para otorgar becas y promociones, o bien extra institucionales, como las que realiza el Sistema Nacional de Investigadores o el propio de las revistas indexadas.

Es claro que hay otros problemas de no menor fondo que deben ser atendidos con la misma importancia, como el que se presenta con la ausencia de lecturas básicas y fundamentales que hayan ido formando el bagaje teórico de las y los jóvenes universitarios, pero también lo es que muchas lecturas trabajadas sin método tampoco garantizan una investigación de calidad. Ambas vertientes deben atenderse y, por lo pronto, el propósito del presente artículo es ocuparse de lo segundo: cómo determinar la validez de una investigación jurídica, a partir de criterios objetivos. Para ello, el artículo dedica unos párrafos a encuadrar la investigación jurídica como una forma de investigación cualitativa, para ocuparse enseguida del tema de la argumentación como criterio de validez del trabajo de investigación de los fenómenos jurídicos.

\footnotetext{
'Sobre el tema han abundado otros colegas que desde luego han hecho aportes importantes. Véanse, sobre todo: FIX (1966), "En torno a los problemas de la metodología del derecho", Revista de la Facultad de Derecho de México, núm. 62, [en línea], disponible en: https://revistas-colaboracion.juridicas.unam.mx/ index.php/rev-facultad-derecho-mx/article/view/26306/23685, LARA (1991), Procesos de investigación jurídica, México, IIJ/UNAM., Ponce (1996), SÁnchez (1997), Metodología de la ciencia del derecho, México, Porrúa., Tamayo (1986), El derecho y la ciencia del derecho, México, IIJ/UNAM., Villoro (1993), Metodología del trabajo jurídico, México, Limusa. y Witker (2008), Metodología jurídica, México, McGraw Hill. Imperdible el trabajo de ÁviLA (2005) "La metodología jurídica en México: un estado del arte, en Cienfuegos, D. Y López Olvera, M.A". Estudios en homenaje a Don Jorge Fernández Ruíz. México: UNAM/IIJ, pp. 1-28, que hace un análisis de los diversos momentos por los que ha pasado la preocupación acerca del método de investigación en las disciplinas jurídicas.
} 


\section{La investigación jurídica como una forma de investigación cualitativa}

La investigación cualitativa se define a contracorriente de la tradición científica de orientación hipotético-deductiva, que encuentra sus raíces en la aproximación epistemológica analítica ${ }^{2}$. Comparte, más bien, presupuestos con la fenomenología, la hermenéutica, la etnometodología, el estructuralismo, el constructivismo y aún con el marxismo, en tanto que su propósito no es la descripción y explicación analítica de los fenómenos que estudia, sino su comprensión. En términos generales, procede inductivamente, desde los datos hacia la teoría y por ello, diversos autores consideran que este tipo de investigación tiene como finalidad construir conocimientos teóricos, en lugar de someterlos a prueba.

La investigación cualitativa es poco rigurosa en términos del control de la subjetividad del investigador, precisamente porque asigna a este último una influencia en la interpretación de la realidad. Se orienta hacia el descubrimiento a través de la heurística, que en este contexto es un componente esencial del pensamiento creativo y de la capacidad de invención que permite inferir el producto del descubrimiento. Lo que se descubre no es, necesariamente, algo objetivo o presente, sino que, dependiendo de la aproximación epistemológica que se asuma, descubrimiento, en este caso, se acerca más a la develación o al esclarecimiento de lo que ha permanecido oculto a los sentidos -estructuras subyacentes, sentido, lo no dicho, lo implícito, lo encriptado o lo revelado. La heurística, así planteada, es más una habilidad que un procedimiento, la habilidad para ir del texto al sujeto, de ahí al intertexto, de nuevo al sujeto, de ahí al contexto, de regreso al texto y así, sucesivamente realizando inferencias interpretativas que consiguen, por así decirlo, rellenar los huecos que se hallan durante el procedimiento, con conocimiento propio, producido por el intérprete ${ }^{3}$.

El rigor está puesto, más bien, en la capacidad para argumentar con solidez las conclusiones a las que se llega. Dependiendo del marco teórico que asuma, el procedimiento de la investigación cualitativa puede considerar incluso que la hipótesis no juega un rol específico como punto de partida de las indagaciones, sino más bien como su punto de llegada. La búsqueda de información es más bien abierta y está dispuesta a captar lo inesperado, lo emergente, para integrarlo como parte de los hallazgos. Ni la medición del fenómeno, ni tampoco la definición de muestras que sean estadísticamente representativas de la población de la que se extraen, son relevantes. Por una parte, eso explica que en la perspectiva cualitativa no se empleen instrumentos precisos de medición; por la otra, que

\footnotetext{
2 Para un análisis detallado de las técnicas y herramientas de la investigación cualitativa, así como de sus fundamentos, véase Delgado Y GutiérRez (1999), Métodos y técnicas cualitativas de investigación en ciencias sociales, Madrid, Síntesis.

3 Construyo esta idea de modo más próximo a la tradición que surge con BAJTin (1989), Teoría y estética de la novela, Madrid, Taurus; y KRISTEva (1997), "Bajtin, la palabra, el diálogo y la novela", en Navarro, D. (comp.). Intertextualité. Francia en el origen de un término y el desarrollo de un concepto, La Habana, UNEAC/Casa de las Américas/Embajada de Francia en Cuba, pero acepto que el problema de esta heurística es que es teórica y que se coincide con la propuesta de Polya: Boscán y KLever (2012), "Metodología basada en el método heurístico de Polya para el aprendizaje de la resolución de problemas matemáticos", Escenarios, vol. 10, núm. 2, julio-diciembre, pp. 7-19.; o Kahneman (2014), Pensar rápido, pensar despacio, México, Debolsillo, en tanto que técnica para resolver problemas. No descarto, por tanto, que sobre todo en investigadores inexpertos, las inferencias realizadas estén afectadas por los heurísticos, de anclaje, proximidad y hasta representatividad, propuestos por KAHNEMAN que representan sesgos en el juicio.
} 
la muestra la constituyan apenas unos cuantos casos -o a veces uno sólo- pues el tipo de inferencia que se hace desde lo cualitativo no busca ser generalizada a la población, sino a presupuestos teóricos u otras variables cualitativas.

En el campo de los fenómenos jurídicos, la investigación cualitativa tiene un amplio espectro de aplicación. De hecho, con frecuencia, las y los juristas investigan mediante el uso de técnicas de investigación cualitativa aun cuando no sea común que las hagan explicitas. Por ejemplo, lo que la mayoría identifica como investigación documentali-que recomiendan hacer mediante la elaboración de fichas-, constituye una forma simple de investigación cualitativa que es realizada sobre un tipo particular de textos -libros y artículos- que en las peores ocasiones apenas logra organizar la información existente como un conjunto de ideas - de otros- en cadenas de citas que no tienen ningún valor heurístico; en la investigación jurídica seria, el análisis de los textos sigue el camino trazado más arriba, en el que el investigador acude al texto, lo interroga, lo compara con otros textos para generar un análisis intertextual, analiza, compara, halla convergencias, divergencias, identifica silencios, vuelve al texto, descubre -devela o esclarece, es decir- el sentido detrás de los textos, interpreta infiere y produce nuevo conocimiento. Con frecuencia, también acude al contexto para ampliar el horizonte de interpretación. No obstante, ello ocurre en la clandestinidad del cubículo, pues de la investigación sólo suelen publicar el resultado.

Pero aún este proceso heurístico -que no es distinto al que se pone en marcha cuando se explora la literatura existente en cualquier disciplina, sin que importe la actitud epistemológica que se asuma o la aproximación teórica de la que se parta- hace muy difícil distinguir entre una investigación que se pretende científica y una opinión bien informada. La clandestinidad del procedimiento en la investigación jurídica complica mucho evaluarla. ¿Qué hacen entonces los juristas para evaluar la investigación jurídica? Lo sepan o no, evalúan su validez científica.

\section{La validez científica en la investigación cualitativa de los fenómenos jurídicos}

En términos generales, la validez científica de una investigación tiene que ver con los criterios que hacen que sus resultados sean aceptados por una comunidad de investigación. Corrientemente se consideran dos tipos de validez científica: la validez interna, que representa la confianza que se tiene en que los resultados de la investigación dependen de un razonamiento correcto (capacidad explicativa), y la validez externa, que está relacionada con qué tanto los resultados se consideran aplicables a situaciones análogas a las estudiadas y representativas de las teorías y paradigmas que los enmarcan (capacidad de generalización).

La validez interna depende, entonces, de la capacidad para explicar que las conclusiones a las que se arriba tienen relación con las premisas de las que se parte; la validez externa, por su parte, se relaciona con la capacidad para generar consenso en la comunidad a la que cada investigadora o investigador pertenece. Como es obvio, los criterios de validez en la investigación cualitativa son, igualmente, cualitativos. Ello los expone a un alta grado de subjetividad, aunque ésta no es necesariamente arbitraria, sino que está sujeta a ciertos controles; según se propone enseguida, en el campo de los fenómenos jurídicos, la validez tanto interna como externa es posible controlarla mediante la argumentación. 


\subsection{La argumentación como criterio de validez de una investigación jurídica}

Como es ampliamente aceptado, la argumentación es, dicho en términos sencillos, la exposición de las razones que sostienen una conclusión, a partir de sus premisas. Las y los juristas están muy familiarizados con la argumentación pues constituye el modo más confiable de validación de las decisiones que toman los operadores jurídicos en los distintos ámbitos en los que se desempeñan: el jurisdiccional, el legislativo, o el de las prácticas jurídicas. De hecho, el famoso jurista polaco Jerzy Wroblesky (2008), afirma que la argumentación también aplica a la investigación jurídica y, aunque ciertamente no dice cómo, los productos de la investigación jurídica revelan, ex post, su estructura argumentativa -o la ausencia de ella.

El tema de la argumentación ha sido prolíficamente tratado, de Toulmin (1958) a Perelman y Olbrecht-Tyteca (1969), pasando por Habermas (1987) y Alexy (1989), pero ha sido Manuel Atienza (2013) quien ha ofrecido una interesante síntesis en la que destaca el rol de la argumentación como un criterio de valoración de la calidad del discurso que se produce en el derecho.

Para el profesor alicantino, es posible identificar tres concepciones básicas de la argumentación: la concepción formal que se centra en la argumentación no como actividad, sino como resultado... de la aplicación de reglas de inferencia ... de la lógica formal ${ }^{4}$; la concepción material, para la que lo esencial no es la forma de los enunciados, sino aquello que hace a los mismos verdaderos o correctos: los hechos naturales o institucionales a que se refieren esos enunciados y la concepción pragmática que contempla la argumentación como un tipo de actividad lingüística, como una serie de actos de lenguaje o un acto de lenguaje complejo 5 . En el primer caso, se trata de establecer la verdad o falsedad formal de los enunciados; los últimos están destinados a plantear, respectivamente, la corrección y la capacidad de persuasión de los argumentos. Aunque en efecto, estas tres aproximaciones refieren a problemas cuya naturaleza puede ser distinta, representan, como afirma Atienza, más bien dimensiones que concepciones acerca de la argumentación que pueden ser evaluadas según la aproximación que se asuma: por su validez lógica ${ }^{6}$ (formal), por su solidez (material) o por su capacidad de persuasión (pragmática). Atienza distingue entre argumento, argumentación y línea argumentativa, lo que hace posible segmentar el discurso jurídico identificando las partes que lo componen:

Una argumentación es el conjunto de pasos, actos de lenguaje y enunciados que median entre el planteamiento de una pregunta inicial -el problema que da lugar a la argumentación- y la respuesta a la misma -la solución. Un argumento es una razón a favor o en contra de una determinada tesis. Y una línea argumentativa es un conjunto de argumentos orientados en un mismo sentido: a defender la tesis o a atacarla. $^{7}$

${ }^{4}$ Atienza, M. (2013), Curso de argumentación jurídica, Madrid, Trotta, p. 110.

5 Ibid, p. 111.

${ }^{6}$ Califico como lógica a la validez que se predica, o no, de la aplicación de una regla de inferencia en el campo de la lógica formal, para distinguirla del concepto de validez científica al que se refiere el presente acápite. Aclaro que, desde luego, no es un término que utilice Atienza.

7 Atienza, M. (2013), op. cit. nota 4, p. 425. 
Aunque el autor se está refiriendo en todo momento a las resoluciones judiciales, con la distinción de estos elementos visibiliza una estructura, una suerte de molde formal que es extrapolable a otros textos jurídicos - un producto de investigación, por ejemplo- que, según demuestre o no validez lógica, solidez o capacidad persuasiva, permitiría distinguir una argumentación buena de una mala. Prevenidos de la advertencia que hace el autor, con base en Aristóteles, de que existe la posibilidad de que la argumentación sólo parezca estar bien construida, cuando en realidad no es así -de lo que se sigue que, no obstante su apariencia, la argumentación resulte falsa o equivocada-, es posible también extrapolar la clasificación aristotélica de las falacias calificando de sofísticos a los textos que, con el propósito de engañar, es decir, con conciencia del error, manipulan las premisas de las que parten para sostener una conclusión que no se sigue de ellas; y de paralogísticos, a los que son producto honesto de un error real, del que su autor no es consciente, por ejemplo, en aquéllos casos en los que, más que producir conocimiento nuevo, la o el investigador sólo está documentando su ignorancia. Es posible, así, tener un marco de valoración para un producto intelectual en el campo jurídico que permitiría, prima facie, distinguirlo como científicamente válido si demuestra serlo lógicamente, o si es sólido o bien si es persuasivo; y científicamente inválido si es un sofisma o un paralogismo.

Así, tendríamos tres parámetros de validez que, en realidad, constituirían dos técnicas simpes de validación de las capacidades explicativa y persuasiva de un argumento o de un conjunto de argumentos, según se exponen a continuación. Los parámetros los constituirían la validez lógica, la solidez argumentativa y la capacidad persuasiva; las técnicas implicarían la combinación de los dos primeros con el tercero, de modo que podrían ser denominadas, respectivamente: formal/persuasiva y material/persuasiva. Estos binomios representan dos momentos que son indisolubles entre sí, uno representa un referente objetivo, sea este formal o material, y el otro uno subjetivo, que supone el juicio de quien realiza la valoración. Sin pretender en absoluto que existe una separación tajante entre ambos momentos, resulta conveniente asumir que el peso que adquiere cada uno de estos elementos del binomio en el momento de la valoración, dependerá del tipo de validez que se quiere determinar. Así el elemento objetivo - formal o material- tendrá más peso en la evaluación de la capacidad explicativa del texto, mientras que el subjetivo lo tendrá cuando lo que se evalúe sea su capacidad para lograr consenso. De este modo, la validez interna descansaría en la primera parte del binomio ${ }^{8}$ y la externa en la segunda.

\subsection{La lógica formal como criterio de validez interna: los argumentos correctos}

Los trabajos producidos dentro de la concepción jurídico formal a la que se refiere Alexy, es decir, aquéllos en los que importa que el argumento este construido correctamente, suelen ser objeto de validación interna mediante una técnica igualmente formal, a través del establecimiento de la validez lógica de sus argumentos, lo que

\footnotetext{
${ }^{8}$ El concepto de validez interna aquí usado se corresponde en lo general con el significado que en 1971 Wroblewsky dio al concepto de justificación interna, como el paso de las premisas a la conclusión; en lo particular, el de validez interna formal, con el de justificación formal, como la que se lleva a cabo con auxilio de la lógica formal, y el de validez interna material, con el de justificación no formal, como el que se auxilia de las teorías no formales como la tópica y la retórica, introducidos también por Wroblewsky, años más tarde, en 1979. Cfr. ATIEnZA (2013), op. cit. nota 4, pp. 103-104.
} 
significa verificar si las conclusiones a las que arriba la argumentación se predican en efecto de las premisas, a través de las reglas de inferencia utilizadas en la lógica proposicional. Producir un texto desde esta perspectiva supone ir concatenando los argumentos de modo tal que unos se prediquen de otros con arreglo a tales reglas de inferencia. De este modo es posible afirmar que, si las reglas de inferencia son el mecanismo de evaluación de la validez lógica de los argumentos, esas mismas reglas pueden, sin duda, ser consideradas como una técnica para garantizar validez interna a la argumentación. Desde esta perspectiva es posible plantear que los productos de la investigación jurídica son formalmente válidos si pueden ser justificados, por ejemplo, con arreglo a la semántica de la lógica proposicional.

La lógica proposicional permite descomponer una idea en las proposiciones que la forman para identificar la relación que guardan entre sí respecto de la conclusión a la que se arriba. Así, es posible asignar un símbolo para representar los argumentos y luego, mediante las reglas de inferencia, verificar si la idea está lógicamente construida. Considérese, por ejemplo, una investigación que tiene como objeto indagar qué doctrina constitucional está detrás de las resoluciones judiciales en México. Dependiendo de la posición teórica que se asuma, habría de hipotetizarse que alguna doctrina está detrás de las resoluciones que emite el máximo tribunal del país. El desarrollo de la investigación podría plantear, por ejemplo, la siguiente afirmación que, para fines de análisis, habría que descomponer en las proposiciones que la conforman para luego identificar también las operaciones lógicas que están en ella implicadas:

En México, la doctrina constitucional de los derechos humanos podría ser principialista (p) o garantista (q). Si fuera principialista (p) habrá resoluciones afectadas de inseguridad jurídica (-r); si fuera garantista (q) no las habría (r). Pero no sería garantista a menos que el interés de las resoluciones judiciales (s) estuviera en la seguridad jurídica (r). Como ello no ha ocurrido (-s), se puede afirmar que hay inseguridad jurídica (-r) y, por tanto, que la doctrina constitucional mexicana no es garantista (q), sino principialista (p).

La simbología sería la siguiente:

$\mathrm{p}=$ la doctrina constitucional podría ser principialista

$\mathrm{q}=$ la doctrina constitucional podría ser garantista

$\mathrm{r}=$ seguridad jurídica

$\mathrm{s}=$ interés de las resoluciones judiciales en la seguridad jurídica

Así, tenemos primero una disyuntiva, que constituye la hipótesis que queremos probar. Nótese que las proposiciones son mutuamente excluyentes, por lo que, si se niega una, necesariamente se afirma la otra (por la aplicación de la regla del modus tollendo ponens):

p v q (o p o q: o la doctrina constitucional es principialista o es garantista)

Luego hay dos líneas argumentativas que forman dos proposiciones condicionales:

$\mathrm{p} \rightarrow-\mathrm{r}$ (si p, entonces, no r: si es principialista, entonces las resoluciones producirán inseguridad jurídica)

$\mathrm{q} \rightarrow \mathrm{r}$ (si q, entonces, $r$ : si es garantista, entonces las resoluciones producirían seguridad jurídica) 
Pero además la afirmación contiene una condicional necesaria que afirma:

$-\mathrm{s} \rightarrow-\mathrm{q}$ (si no s, entonces, no q: si el interés de las resoluciones no está en la seguridad jurídica, entonces la doctrina constitucional no sería garantista)

Si se afirma que:

-s (no s: el interés de las resoluciones no está en la seguridad jurídica)

Entonces, aplicando el modus ponendo ponens puede concluirse que:

$\mathrm{r}^{\wedge}-\mathrm{q}$ ( $r$ y no q: hay inseguridad jurídica y que la doctrina constitucional mexicana no es garantista.)

La forma del argumento es válida. Obsérvese, sin embargo, que no se cuestiona la validez de las premisas que dan forma a las dos proposiciones que representan las dos líneas argumentativas. Claramente no está bajo análisis el razonamiento que lleva a afirmar que una posición implica seguridad jurídica y la otra no, por lo que estas premisas podrían ser falsas, a pesar de que el argumento está bien construido. De ahí que se requiera de un análisis de otro nivel que permita indagar si, no obstante que el argumento es correcto, es también válido. En este punto, esta consideración apela a la capacidad persuasiva del argumento que, aún dentro de los límites de la lógica formal, asciende al nivel pragmático del lenguaje que, igualmente formalizado, se expresa por ejemplo en las llamadas falacias formales que los lógicos han identificado como fuentes de invalides de los argumentos. Las falacias representan acuerdos pragmáticos sobre el porqué un argumento es invalido $\mathrm{y}$ en ese sentido suponen una forma objetiva de demostrar la invalidez y de cuestionar el alcance persuasivo de un argumento?.

La simpleza de este procedimiento es manifiesta pues, como se ve, la idea es la de traducir un texto construido en lenguaje natural a un lenguaje proposicional, de modo que se facilite verificar la relación de implicación dentro de la argumentación. Cabe señalar que, si bien en este caso el ejemplo se ha efectuado acudiendo a la lógica proposicional, cuando las premisas no son proposiciones, es decir, cuando de ellas no se puede decir que son verdaderas o falsas, porque ello depende de variables cuyos valores son ignotos, siempre es posible recurrir a otros lenguajes formales, como el de la lógica de predicados,

9 Dentro de las falacias formales están las siguientes [MARTínez (2010), Metodología jurídica y argumentación, Madrid]:

a) negación del antecedente:

$\mathrm{p} \rightarrow \mathrm{q}$

$-\mathrm{p}$

$-\mathrm{q}$

b) afirmación del consecuente:

$\mathrm{p} \rightarrow \mathrm{q}$

$\mathrm{q}$

$\mathrm{p}$

c) Non sequitur.

$p v q$

$p($ o bien $q)$

-----

$-q(o$ bien $-p)$ 
que admiten cuantificadores. El procedimiento se hace más complejo, pero el principio es el mismo: la ausencia de validez interna invalidará la argumentación y, si ello anula la capacidad explicativa del texto, terminará por invalidar la investigación.

\subsection{El modelo de razonamiento práctico de Toulmin como criterio de validación interna: los argumentos razonables}

La capacidad explicativa en la concepción material de la argumentación, que descansa particularmente en la solidez de las premisas más que en el resultado de la argumentación, debería poder ser evaluada mediante una técnica de validez material/persuasiva, que se ocupará de saber qué tan robustas resultan ser esas premisas. Aunque han sido desarrollados con otros fines, es posible identificar al menos un procedimiento que evalúa desde esta perspectiva la argumentación jurídica: el modelo de argumentación de Stephen Toulmin (cit.).

Stephen Toulmin adquirió notoriedad a partir de la presentación de sus ideas en torno a la validez del razonamiento práctico y de las ventajas que observa en este último respecto del lógico formal. Para este autor, es posible escudriñar el modo en el que las personas sostienen sus aseveraciones $y$, con base en él, modelar un procedimiento en aras de hallar un camino seguro entre las premisas y la conclusión que, si bien no puede reputarse como verdadera, si puede serlo como razonable. El modelo general que presenta suele esquematizarse del siguiente modo:

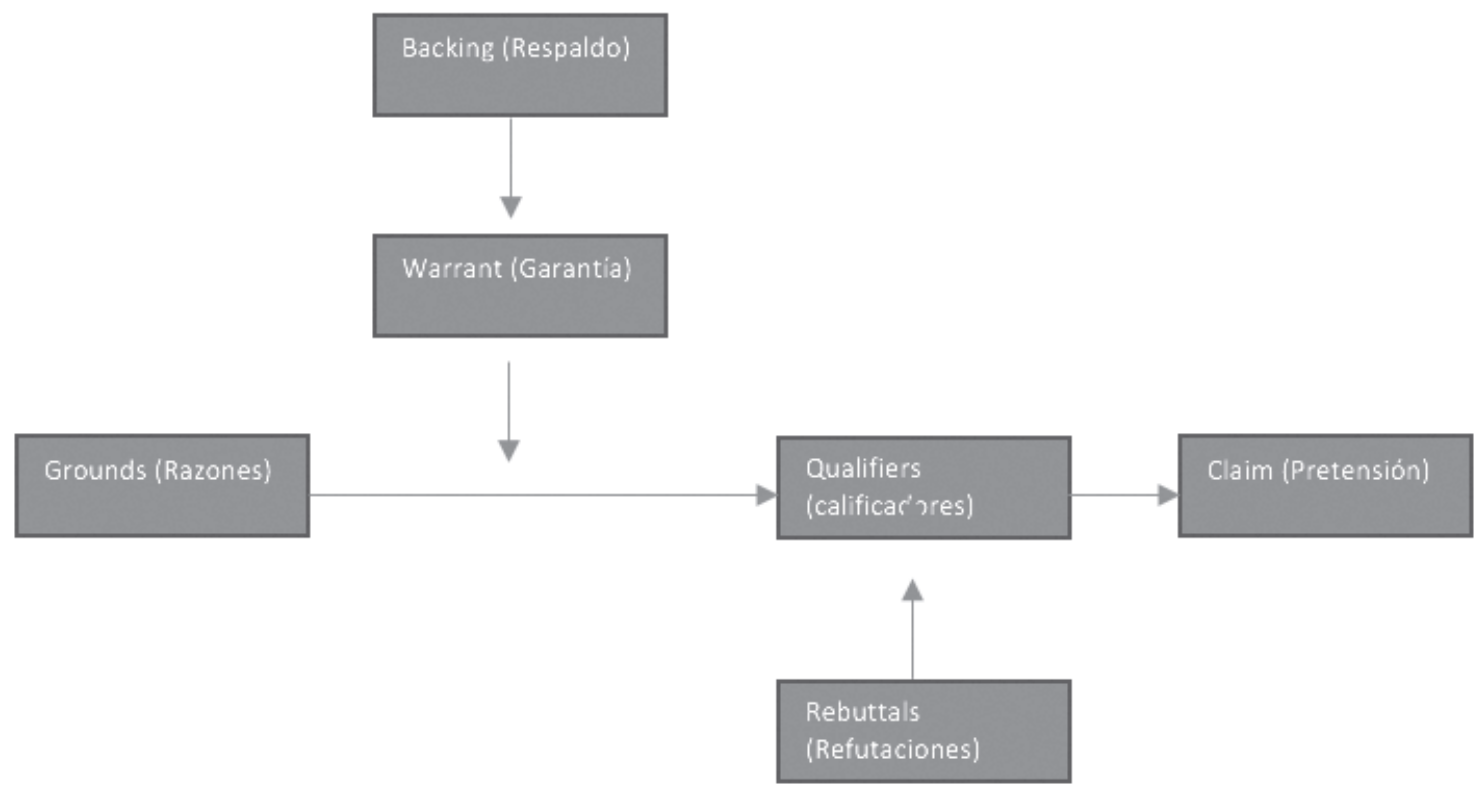

Para Toulmin, la pretensión (Claim) corresponde al mismo tiempo al punto de partida y al punto de destino de la argumentación; ésta se basa en un conjunto de razones (Grounds) que constituyen el apoyo de la pretensión cuya validez se funda, por una parte, en el respaldo (Backing) de dichas razones y en la garantía (Warrant) que constituye la regla que autoriza el paso de unos enunciados a otros. Toulmin introduce además lo que llama cualificadores modales (Qualifiers), que son adverbios de modo que relativizan la fuerza de la conclusión, así como las refutaciones (Rebuttals) que constituyen excepciones o razones que refutan la pretensión. Este modelo ofrece un procedimiento que permite 
distinguir, en función de la fortaleza de las razones, de la autoridad del respaldo y de la garantía, así como de la identificación de las refutaciones, una conclusión segura amparada por la relatividad del adverbio que se elija para matizar; por ejemplo el enunciado: Peter nació fuera de México, entonces es extranjero es cierto, sólo si se cumplen determinadas condiciones que es necesario ir mostrando en la medida en la que avanza el proceso de argumentación. De hecho, en la perspectiva de Toulmin, así planteado, representa un argumento débil. Por ello el autor señala la necesidad de incorporar una garantía que sirva de sostén, por ejemplo, la siguiente: los nacidos fuera de México son extranjeros que refuerza el enunciado para dejarlo del siguiente modo:

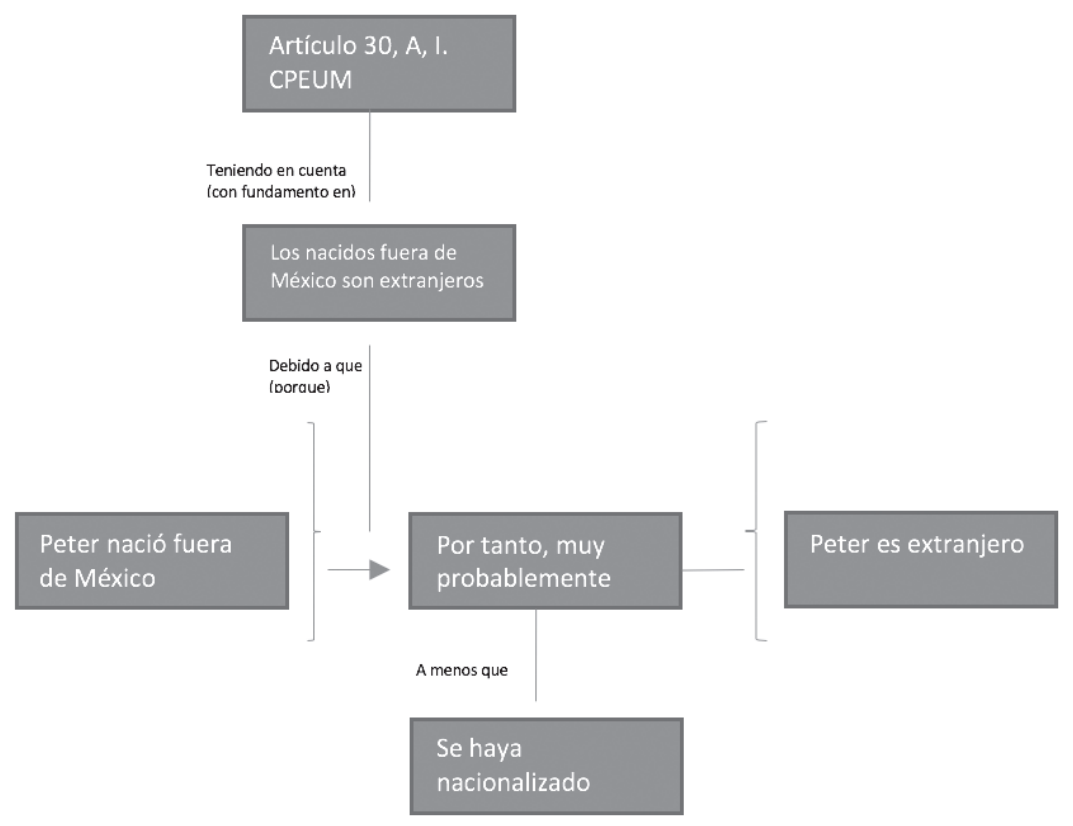

Peter nació fuera de México; [debido a que] los nacidos fuera de México son extranjeros, entonces Peter es extranjero.

Pero aún este enunciado puede reforzarse más, si a la garantía se le incorpora un respaldo, por ejemplo: El artículo 30, apartado A, fracción I, de la Constitución Política de los Estados Unidos Mexicanos, dice que son mexicanos por nacimiento los que nazcan en territorio de la República, sea cual sea la nacionalidad de sus padres. Así el argumento se fortalece para quedar del siguiente modo:

Peter nació fuera de México; [debido a que] los nacidos fuera de México son extranjeros, [teniendo en cuenta] el artículo 30, apartado A, fracción I, de la CPEUM, entonces Peter es extranjero.

Sin embargo, Toulmin considera aún un par de elementos más: por una parte, considera la posibilidad de que existan razones que refuten o sean excepciones a la garantía, por ejemplo, que Peter se haya nacionalizado mexicano; por la otra, introduce los cualificadores modales, que le permiten graduar los niveles de certeza del argumento. Completo, el enunciado quedaría así: 
Peter nació fuera de México; [debido a que] los nacidos fuera de México son extranjeros, [teniendo en cuenta] el artículo 30, apartado A, fracción I, de la CPEUM, a menos que se haya nacionalizado, entonces, muy probablemente, Peter es extranjero.

Gráficamente el argumento quedaría expresado del siguiente modo:

Como puede verse: 1) el enunciado supone un vínculo entre un hecho cuyo nexo con la pretensión se valida mediante la garantía que, 2) es una suerte de presupuesto generalizado, -una proposición hipotética-, que se respalda, a su vez, en un dato que la autoriza, pero que, 3) al mismo tiempo, admite un matiz, debido a la posibilidad de que existan otros hechos que la contradigan, motivo por el cual, 4) la incorporación del cualificador modal gradúa la fuerza o probabilidad de la aserción. Así, la evaluación de la estructura argumentativa puede medirse, por así decirlo, no solamente en función de la satisfacción del procedimiento mismo de argumentación -es decir que base sus aserciones en la presentación de razones que se validan, refuerzan, respaldan, consideran sus excepciones y matizan- sino en los contenidos mismos de esas razones.

Cabe señalar que Toulmin asume que el proceso de argumentación es dialógico y que, la estructura de su modelo representa, por así decirlo, una suerte de contradictorio hipotético que se da en la práctica, por ejemplo, entre dos personas que se disputan la razón sobre la pretensión del argumento. Por ello es por lo que, en el mismo sentido, supone que las razones contenidas en la garantía, el respaldo y las refutaciones no aparecen todas de una vez, porque si así fuera, no habría una discusión ninguna sobre tal pretensión. Sin embargo, aplicado el modelo al terreno que ocupa a este texto, que es el de la investigación de los fenómenos jurídicos, es posible asumir que ese contradictorio ocurre en dos niveles que apelan a la dimensión pragmática del lenguaje: uno en el dialogo interno que tiene con su propio bagaje teórico el investigador -y que representa entonces las conjeturas y refutaciones, para usar un término de Popper, que se hacen durante el proceso de investigación- y dos, en el diálogo externo que entabla con sus pares, donde la investigación habrá de mostrar su capacidad persuasiva. Dentro del campo de la investigación jurídica, un producto intelectual del que se diga que internamente es materialmente válido, debería mostrar, al menos, que sus conclusiones se siguen de premisas de las que se ha probado que sus contenidos son válidos, mediante las garantías, respaldos y refutaciones pertinentes, lo que debería significar también, aceptados por su comunidad de investigación. Para la verificación de la validez interna de la investigación jurídica de tipo material, son aplicables en este caso las falacias lógico-materiales que igualmente constituyen acuerdos sobre cuándo, a pesar de su apariencia, se está frente a argumentos inválidos ${ }^{10}$.

\subsection{La validez externa de la investigación jurídica: la fase persuasiva de la argumentación}

Que una investigación sea internamente válida no garantiza en absoluto que posea validez externa. De hecho, la validez interna es condición necesaria pero no suficiente de la vali-

\footnotetext{
${ }^{10} \mathrm{Al}$ igual que en la lógica formal, en la aproximación material también existen falacias, entre ellas, las falacias ad hominen, ad ignorantiam; ad misericordiam; ad populum, ad verecundiam, petitio principii, los falsos dilemas, entre otras. Cfr. MARTínEZ, op cit. nota 9.
} 
dez externa. Por ello, una vez probada la capacidad explicativa, ya sea formal o material, de una investigación jurídica, y sólo si ésta ha pasado la prueba de validez interna que corresponda, es posible avanzar hacia la valoración de su capacidad de generalización, o bien, como se ha insistido, a su potencial de persuasión frente al consenso de la comunidad de investigación a la que su autor o autores pertenezcan.

La validez externa, como se ha dicho, representa la capacidad de generalización de los resultados de una investigación y, de modo más exacto en el terreno de la investigación cualitativa -dentro de la cual se enmarca en este texto la investigación jurídica- por su capacidad para ser aceptada por el consenso que prevalezca en la comunidad de investigación a la que pertenece una o un investigador. Lo que esto significa es que, sin mayor pretensión, una investigación jurídica posee validez externa si la comunidad de investigación en la que se inscriben sus autores, se la otorga. Aunque esta idea puede generar incertidumbre $-\mathrm{y}$ de hecho la genera porque en muchas ocasiones estos acuerdos se disfrazan o de plano no se reconocen- no se puede escatimar valor al consenso, que al final, tiene un importante potencial constitutivo. El planteamiento se basa, por supuesto, en la sociología del conocimiento de Kuhn (2013) pero más adecuadamente en Habermas (cit.) y su idea acerca de las comunidades de comunicación, de modo tal que se asume que en campos donde la certidumbre debe dejar el protagonismo a la razonabilidad, la posibilidad de existencia de consensos, así en plural, es un hecho. También haya respaldo en la afirmación que hicieran Perelman y Olbrechts-Tyteca en la introducción a su Tratado de Argumentación de que toda argumentación se desarrolla en función de un auditorio ${ }^{11}$. Así que, vista de este modo, la validez externa de la investigación cualitativa asemeja la validez por jueces que se ocupa en las ciencias sociales y algunas de la naturaleza, donde los criterios los fija una comunidad de pares, que va ganando reputación como autoridades en los temas propios de la disciplina de la que se trate. Estos acuerdos tienen una función correctiva que, como resultado de la argumentación ilimitada a la que se refiere el propio Habermas, produce los consensos. De ahí que revisar las reglas de la argumentación del discurso práctico pueda contribuir a construir un nivel de análisis que someta a prueba la capacidad persuasiva de un texto jurídico.

Para Alexy, de hecho, el discurso jurídico constituye una forma especial del discurso práctico general, en los términos en los que lo formulo Jürgen Habermas en su Teoría de la Acción Comunicativa. Alexy ve al derecho como un discurso racional y, en tanto que tal, lo supone sujeto a las reglas del discurso práctico general, así como a otras que aplicarían sólo al discurso jurídico. De hecho, para Alexy, que un discurso práctico (jurídico) sea correcto depende de que haya sido el producto de un procedimiento. Como se ha dicho, con base en Habermas, diseña entonces un conjunto de reglas que, dividas en varios grupos que las identifican con una función en particular, han sido consideradas como una especie de código que regula la argumentación jurídica ${ }^{12}$.

\footnotetext{
${ }^{11}$ Perelman y Olbrechts-Tyteca (1969), Tratado de argumentación. La nueva retórica, Madrid, Gredos., p. 36.

12 Estas reglas son bien conocidas, a saber:

Reglas fundamentales. Las reglas fundamentales son condición de posibilidad de cualquier comunicación lingüística que aspire a la certeza -como en las ciencias empíricas- o a la corrección -como en la retórica o la dialéctica. En este sentido, no son privativas del discurso práctico, sino que resultan aplicables también al discurso teórico. Estas reglas plantean los principios de no contradicción, sinceridad, universalidad y uso común del lenguaje. Alexy las formula de la siguiente manera:

Ningún hablante puede contradecirse.
} 
Las reglas de Alexy suponen coherencia, congruencia y compromiso con el proceso de argumentación y, aunque a veces expresan propiedades del discurso, están referidas básicamente al sujeto productor de los argumentos. Vale señalar que, salvo el caso de las

Todo hablante sólo puede afirmar aquello que el mismo cree.

Todo hablante que aplique un predicado " $F$ " a un objeto "a", debe estar dispuesto a aplicar " $F$ " también a cualquier otro objeto igual a "a", en todos los aspectos relevantes.

Todo hablante solo puede utilizar aquellos juicios de valor y de deber que afirmaría asimismo en todas las situaciones en las que afirmase que son iguales en todos los aspectos relevantes.

Distintos hablantes no pueden usar la misma expresión con distintos significados.

Reglas de razón. Son condiciones de racionalidad del discurso

Todo hablante debe, cuando se le pide, fundamentar lo que afirma, a no ser que pueda dar razones que justifiquen el rechazar una fundamentación

Quien pueda hablar, puede tomar parte en el discurso

Todos pueden problematizar cualquier aserción

Todos pueden introducir cualquier aserción en el discurso

Todos pueden expresar sus opiniones, deseos y necesidades.

A ningún hablante puede impedírsele ejercer los anteriores derechos mediante coerción interna o externa al discurso.

Reglas sobre la carga de la argumentación. Son reglas de carácter esencialmente técnico destinadas a facilitar la argumentación, especialmente en los casos en los que atenerse irrestrictamente a las reglas fundamentales y de razón bloquee el discurso.

Quien pretenda tratar a una persona "a" de manera distinta que a una persona "b", está obligada a fundamentarlo

Quien ataca una proposición o una norma que no es objeto de la discusión debe dar razones para ello.

Quien ha aducido un argumento sólo está obligado a dar más argumentos en caso de contraargumentos.

Quien introduce en el discurso una afirmación o manifestación sobre sus opiniones, deseos o necesidades que no se refiera como argumento a una anterior manifestación, tiene, si se le pide, que fundamentar porque introdujo esa afirmación o manifestación.

Formas de los argumentos. Se trata del tipo de argumentos que fundan enunciados normativos en el discurso práctico. Alexy distingue dos:

por referencia a una regla o bien,

señalando sus consecuencias.

Reglas de fundamentación

Quien afirma una proposición normativa que presupone una regla para la satisfacción de intereses de otras personas, debe poder aceptar las consecuencias de dicha regla también en el caso hipotético de que él se encontrara también en la situación de aquellas personas.

Las consecuencias de cada regla para la satisfacción de los intereses de cada uno deben poder ser aceptadas por todos.

Toda regla debe poder enseñarse en forma abierta y general.

Las reglas morales que sirven de base a las concepciones morales del hablante deben poder pasar la prueba de su génesis histórico-crítica. Una regla moral no pasa semejante prueba si:

$\mathrm{Si}$ aunque originariamente se pudiera justificar racionalmente, sin embargo, ha perdido después su justificación, o

Si originariamente no se puede justificar racionalmente y no se pueden aducir tampoco nuevas razones que sean suficientes.

Las reglas morales que sirven de base a las concepciones morales del hablante deben poder pasar la prueba de su formación histórica individual. Una regla moral no pasa semejante prueba si se ha establecido sólo sobre la base de socialización no justificables.

Hay que respetar los límites de realizabilidad realmente dados.

Reglas de transición

Para cualquier hablante y en cualquier momento es posible pasar a un discurso teórico.

Para cualquier hablante y en cualquier momento es posible pasar a un discurso de análisis de lenguaje.

Para cualquier hablante y en cualquier momento es posible pasar a un discurso de teoría del discurso. 
que llama formas de los argumentos, que como afirma Atienza, son también reglas y que, reconducidas -como hace este último autor- al modelo de Toulmin, pueden implicar la validación de los contenidos de las premisas supuestas en tales formas, en general se trata de reglas que apelan a la regulación del discurso y, en ese sentido, puede considerarse que se trata de formas periféricas al mismo.

Al igual que Toulmin con su modelo, Alexy no pensó este conjunto de reglas como un mecanismo de validación del producto de la reflexión jurídica aplicada a la investigación. De hecho, como el matemático inglés, el jurista alemán -lo mismo que Habermas-pensaba en situaciones de habla cotidiana conformadas dialógicamente en la que la argumentación se construye en la interacción entre quien argumenta y un oponente, con la finalidad de obtener un consenso. De ahí que sus reglas, como es también el interés de Habermas, busquen servir como criterios de legitimidad de un discurso que se pretende correcto (o verdadero, según se trate de un discurso práctico o teórico), inteligible y veraz, en el sentido de sincero y confiable.

Se trata, como puede apreciarse, de una situación ideal que presupone, justo, un compromiso entre los hablantes que, ciertamente se aleja notablemente de la forma en la que se argumenta en la vida real. Esta idealidad, que sería la característica del discurso racional, ha supuesto importantes críticas a Alexy. Como dice Atienza la argumentación jurídica, en todas sus instancias, no puede reducirse a un único tipo de diálogo, el diálogo racional: una de las principales críticas que cabe hacer a la teoría de Alexy es haber realizado ese tipo de reducción. ${ }^{13}$

Pero tratándose del discurso científico-jurídico, que, si se quiere distinguirlo de meras opiniones, debe concebirse como un discurso controlado, la extrapolación de estas reglas al campo de la investigación científica de los fenómenos jurídicos, como constitutivas de una técnica de validación interna del discurso académico del derecho puede ensayarse, al menos por las siguientes razones.

En primer lugar, porque Alexy -igual que Toulmin y por supuesto, Habermas- no concibe la argumentación como una serie de proposiciones, sino como una serie de actos de habla ${ }^{14}$. Así el discurso académico jurídico plasmado en un borrador, en un reporte, o en cualquier otro soporte, publicado o inédito, puede considerarse como una serie de actos de habla, producidos por un hablante (el investigador) con la intención de decir algo con significado. Más allá, en segundo lugar, el discurso jurídico académico es, en función de los distintos momentos en los que se aplica, constatativo, regulativo y representativo, lo que significa que busca que sus aserciones sean ciertas (por ejemplo, cuando se apela a hechos) correctas (como cuando se apela al método, a los procedimientos, a las técnicas y a otros criterios normativos) y además veraces (como cuando se formulan conclusiones, de las que se espera sinceridad). Finalmente, el discurso jurídico académico tiene, asimis-

\footnotetext{
${ }^{13}$ Atienza, M. (2013), op. cit. nota 4, p 372.

${ }^{14}$ De Austin a Searle (1994) y de ahí a Habermas, el concepto de acto de habla ha pasado de distinguir entre locución, ilocución y perlocución en el primero de estos autores para diferenciar el acto de hablar, la intención y el efecto producido con ello (Austin, 1990), a identificar locución e ilocución en SeArLe (1994), -quien más bien distingue el contenido proposicional de una oración, y su intención en la ilocución, pero mantiene la diferencia respecto del efecto que causa el lenguaje en su destinatario como perlocución, y a HABERMAS (1987), quien distingue como ilocucionarios los actos de habla destinados al consenso y como perlocucionarios, aquéllos concebidos estratégicamente para producir una acción.
} 
mo, una pretensión consensual. En el sentido de Habermas, el discurso jurídico académico constituiría sin duda, un conjunto de actos de habla ilocucionarios.

De lo anterior se sigue que es posible considerar el discurso jurídico académico como una forma especial del discurso jurídico general que se distingue de este último por ser racional. Así, extrapolarle las reglas de Alexy debería ser posible. Hacerlo supone, sin embargo, una selección de aquellas reglas que pueden connotarse al ámbito propiamente académico y, enseguida, una resignificación, en ese marco, de la forma en la que Alexy las definió originalmente. De este modo las reglas tendrían la función de servir como un parámetro exterior para la regulación del consenso entre pares y constituirían, por así decirlo, una condición necesaria, aunque no suficiente, para la persuasión. Así, las reglas reformuladas quedarían como sigue ${ }^{15}$ :

${ }^{15}$ La transición entre las reglas originales de Alexy y las que aquí se proponen sería la siguiente: Reglas de coherencia

Ningún hablante investigador puede contradecirse.

Todo hablante investigador sólo puede afirmar aquello que el mismo eree postula.

Todo hablante investigador que aplique un predicado " $\mathrm{F}$ " a una situación objeto "a", debe estar dispuesto a aplicar " $F$ " también a cualquier otra situación objeto igual a "a", en todos los aspectos relevantes.

Todo hablante investigador solo puede utilizar aquellos juicios de valor y de deber que afirmaría asimismo en todas las situaciones en las que afirmase que son iguales en todos los aspectos relevantes.

Distintos hablantes investigadores no pueden usar la misma expresión con distintos significados, a menos que se efectúe una traducción.

Reglas de razón.

Todo hablante investigador debe etando se le pide fundamentar lo que afirma, a no ser que pueda dar razo= nes que justifiquen el reehazar una fundamentaeión.

Quien pueda hablar, puede tomar parte en el diseurso. Fodos pueden problematizar eualquier asereión

Todos pueden introducir cualquier aserción en el discurso

Todos pueden expresar sus opiniones, deseos y necesidades.

Quien tenga algo que argumentar puede ser considerado, en la medida de lo razonable, en la discusión.

A ningún hablante investigador puede impedírsele eximírsele de ejereer cumplir con los anteriores tereehos requisitos mediante eoereión interna o externa al disetriso.

Reglas sobre la carga de la argumentación.

Quien pretenda tratar a una persona un argumento "a" de manera distinta que a tha persona un argumento "b", está obligado a fundamentarlo.

Quien ataca una proposición o una norma que no es objeto de la discusión debe dar razones para ello.

Quien ha aducido un argumento sólo está obligado a dar más argumentos en caso de contra argumentos.

Quien introduce en el discurso una afirmación o manifestación sobre sus opiniones, deseos o necesidades que no se refiera como argumento a una anterior manifestación, tiene, si se le pide, que fundamentar porque introdujo esa afirmación o manifestación.

Formas de los argumentos.

por referencia a una regla o bien,

señalando sus consecuencias.

Reglas de fundamentación.

Quien hace una afirmación una proposieión normativa que presupone con base en una regla para la satisfacción del interés de etras personas un argumento, debe poder aceptar las consecuencias de dicha regla también en el caso hipotético de que él se eneontrara también en la situaeión de aquellas personas de argumentos similares, aplicados a otras situaciones.

Toda regla debe poder enseñarse en forma abierta y general.

Las reglas morales justificaciones que sirven de base a las concepciones morales del hablante investigador deben poder pasar la prueba de su génesis histórico-crítica. Una regla moral justificación no pasa semejante prueba si: 


\section{Reglas de coherencia (textual)}

Este primer conjunto de reglas estaría destinado a probar que hay una estructura en el texto y que ella obedece a una dirección que gobierna la argumentación, de modo tal que las unidades que lo componen se relacionan entre sí para otorgarle sentido. La coherencia textual tendría la función de permitir que el hilo argumentativo lleve de una unidad semántica a otra a favor del argumento central.

Ningún investigador debe contradecirse. Si el texto producido por un investigador sostiene "A", no puede al mismo tiempo, sostener "no A" a no ser que ello sirva a la afirmación de "A", como ocurre con un argumento de reducción al absurdo.

Todo investigador sólo puede afirmar aquello que el mismo postula. Esta regla supone la concordancia con los propios postulados o sistema de postulados, a menos que se produzca convicción en otros distintos por la vía de una confrontación racional. Se podría plantear como una especie de coherencia paradigmática o epistémica, como la que se espera de quien, formado, por ejemplo, en el positivismo, debería mantener sus argumentos sólo dentro de este paradigma, so pena de tener que reconocer que se ubica en uno distinto.

Todo investigador que aplique un predicado " $F$ " a una situación "a", debe estar dispuesto a aplicar " $F$ " también a cualquier otra situación igual a " $a$ ", en todos los aspectos relevantes. La coherencia se garantiza por la semejanza de las situaciones a las que se aplica un predicado, como acontece en el argumento analógico.

Todo investigador solo puede recurrir a aquellos juicios de valor y de deber que afirmaría asimismo en todas las situaciones en las que afirmase que son iguales en todos los aspectos relevantes. Esta regla puede reinterpretarse como coherencia respecto del marco valorativo que un investigador asume. En el campo de las ciencias sociales y de las humanidades, la producción científica no es independiente de un conjunto de valores que, de modo explícito o no -de hecho, casi nunca de modo explícito- orientan al investigador desde y hacia posturas detrás de las cuáles hay valores -más o menos liberales o conservadoras, por poner un ejemplo. La regla no exige hacer explícito este marco, lo que postula es la coherencia con el mismo.

Distintos investigadores no pueden usar la misma expresión con distintos significados, a menos que se efectúe una traducción. La reinterpretación de esta regla asegura el entendimiento de modo que si un concepto " $A$ " significa " $F$ " en una comunidad o una tradición científica "X" y el mismo concepto "A" significa "B" en una comuni-

Aunque originariamente se pudiera justificar racionalmente, sin embargo, ha perdido después su justificación, o Si originariamente no se puede justificar racionalmente y no se pueden aducir tampoco nuevas razones que sean suficientes.

Las reglas morales justificaciones que sirven de base a las concepciones morales del hablante deben poder pasar la prueba de su formación histórica individual. Una regla moral justificación no pasa semejante prueba si se ha establecido sólo sobre la base de socialización no justificable.

Hay que respetar los límites de realizabilidad realmente dados.

Reglas de transición

Para cualquier hablante y en cualquier momento es posible pasar a un discurso teórico.

Para cualquier hablante y en cualquier momento es posible pasar a un discurso de análisis de lenguaje.

Para cualquier hablante y en cualquier momento es posible pasar a un discurso de teoría del discurso. 
dad o en una tradición científica "Y", "A" sólo puede usarse con el significado "F" dentro de la comunidad o tradición "X" y sólo puede usarse con el significado "B" en la comunidad o tradición "Y"; y nunca con el significado "F" en ésta última, o con el significado " $\mathrm{B}$ "en la primera, a menos que se efectúe una traducción. En consecuencia, esta regla aseguraría:

Que un investigador utilice o interprete como "B" un concepto "A", sabiendo que tal significado " $\mathrm{B}$ " es el que se le ha asignado en una comunidad o tradición científica distinta a aquélla a la que se dirige, donde el mismo concepto " $\mathrm{A}$ ", significa " $F " 16$.

Que un investigador utilice los conceptos de los que se sirve siempre con el mismo significado, a menos que explicite las razones por las $-\mathrm{y}$ los casos en los- que lo utiliza con un significado distinto ${ }^{17}$.

Un caso especial que también debería cubrir esta regla — que como se ha dicho tiene como función garantizar el entendimiento- es el de dos o más conceptos objetivos distintos que, sin embargo, objetiva o simbólicamente significan lo mismo, a diferencia de los casos anteriores donde un mismo concepto objetivo puede significar cosas distintas. Así, un investigador que analiza, por ejemplo, dos tradiciones o sistemas jurídicos que poseen conceptos distintos para significar una misma cosa, se obliga a transcribir el o los conceptos de que se trate y a ofrecer la traducción correspondiente. De este modo, quien accede al texto puede juzgar el sentido de la traducción y aceptarla o no. La regla opera, tanto para las citas en otro idioma, como para conceptos que, proviniendo de culturas distintas, encuentran significados que pueden equipararse ${ }^{18}$.

\section{Reglas de razón}

Aplicadas al contexto de la investigación jurídica, estas reglas son condición de racionalidad del discurso académico, lo que significa que aportan rigor científico, dada la exigencia de cimentar las afirmaciones en información verificable y susceptible asimismo de evaluación, y la de discutir con todos aquéllos que hayan hecho planteamientos relevantes al tema que se investiga.

\footnotetext{
${ }^{16}$ Por ejemplo, es sabido que Luigi Ferrajoli ha reinterpretado el concepto de validez de Kelsen, quien lo identifica con vigencia, para asignarle dos significados en tanto se trate de validez en sentido lato -que se corresponde con la vigencia de Kelsen- y validez en sentido estricto -que se corresponde con el que Ferrajoli mismo llama deber ser del derecho. Si el investigador formado en la tradición del garantismo escribe un texto que trasciende a otras tradiciones, se obliga a explicar cuándo usa validez con un significado y cuándo en otro. Habitualmente, en estos casos, para aclarar el significado al que se alude, se utiliza la alocución en el sentido de...; es decir que habría que escribir, por ejemplo: validez en el sentido de Kelsen o bien validez en el sentido de Ferrajoli.

${ }^{17}$ Con el mismo ejemplo, esta regla prevendría que ese investigador usara, en el mismo texto, unas veces validez en sentido kelseniano y otras en sentido ferrajoliano, sin aclarar cuando lo usa con uno u otro significado.

${ }^{18}$ Este es el caso de la llamada hermenéutica diatópica de Boaventura de Sousa Santos, quien se ha ocupado, por ejemplo, de hallar la preocupación isomórfica con respecto a la dignidad humana entre el concepto occidental de derechos humanos, el concepto islámico de umma y el concepto hindú de dharma. Sousa Santos (2010), Refundación del Estado en América Latina. Perspectivas desde una epistemología del Sur, México, Siglo XXI, p. 54.
} 
Todo investigador debe fundamentar lo que afirma. Esta regla es fundamental para distinguir una opinión, una actitud o un valor, de una aserción que tiene pretensión de verdad y bien puede hacer referencia al modo en el que la fortaleza de las premisas se funda en la solidez de esos fundamentos, que se identifican con el aparato crítico de una investigación. De aquí se sigue, por ejemplo, que ningún texto jurídico que aspire a ser considerado científico podría prescindir de soporte teórico sólido y sujeto asimismo a rigor académico.

Quien tenga algo que argumentar puede ser considerado, en la medida de lo razonable, en la discusión. Esta regla reformula externamente la propuesta por Alexy, pero mantiene su sentido y su pertinencia. El sentido dialógico del discurso jurídico académico puede referir al menos a tres momentos importantes: el diálogo del investigador con sus fuentes, el diálogo entre las mismas fuentes y el diálogo que se busca entre el texto producido y el auditorio al que se dirige. La regla implica, por tanto, no dejar deliberadamente fuera autores que tienen argumentos relevantes para la discusión, en ninguno de los tres momentos referidos. El adverbio "en la medida de lo razonable" señala al mismo tiempo la imposibilidad fáctica de incluirlos a todos y la obligación de no omitir a aquéllos cuyos argumentos, aún contrarios a los propios, deberían ser considerados para enriquecer la discusión, pero habría de exigirse que se incluyera sin duda a aquellas investigaciones que configuran el estado del arte en el terreno en el que se realiza la investigación.

A ningún investigador puede eximírsele de cumplir con los anteriores requisitos. En tanto que este conjunto asegura la racionalidad del discurso, en este caso de un discurso controlado como el de la investigación jurídica, lo que para el lenguaje natural son derechos, aquí se tornan requisitos, es decir, requisitos de racionalidad: fundar lo que se afirma y considerar todos los argumentos pertinentes, con independencia de que se muestren a favor o en contra del discurso.

\section{Reglas sobre la carga de la argumentación}

Estas reglas aseguran la integridad de la discusión dentro de un texto. Que el texto sea íntegro significa que haya sido capaz de incorporar los argumentos, incluso aquéllos que son emergentes, en un todo homogéneo que los sintetice.

Quien pretenda tratar un argumento " $a$ " de manera distinta que a un argumento " $b$ ", está obligado a fundamentarlo. En el contexto de la investigación jurídica, esta regla podría considerarse como un requisito de congruencia. Previene que algunos argumentos sean tratados de una forma distinta a otros sin justificación. Indirectamente previene asimismo contra el prejuicio, dado que implica reconocer cuándo un argumento está motivado por emociones, lo que termina por relativizar su contenido racional. Así, esta regla implicaría lo siguiente:

Que, para garantizar la congruencia de un texto, los argumentos en los que se sostiene deben ser del mismo tipo, so pena de conducir a confusión. Un texto sostenido sólo -o predominantemente- en argumentos emocionales es válido, pero no es científico (por ejemplo, un cuento, una novela o un relato o un artículo periodístico).

Que, en principio, en un texto científico, todos los argumentos deben ser racionales y, por tanto, cualquier argumento que esté motivado en emociones, debe ser excluido. 
Que, en caso de considerar necesario un argumento emotivo, es igualmente necesario fundamentar las razones de su uso.

Quien ataca una proposición o una norma que no es objeto de la discusión debe dar razones para ello. Esta regla plantea la necesidad de mantener un hilo argumentativo que muestre el camino de las premisas a la conclusión y viceversa, que a la vez previene la incorporación de argumentos ajenos a la discusión, a menos que haya razones para hacerlo. Este es el caso, por ejemplo, de una digresión; la regla impone la carga de justificarla, lo cual puede ocurrir de dos maneras:

1. Si la digresión se da en el conjunto del texto, será necesario exponer las razones de ello para que el interlocutor comprenda que se trata de una discusión que es útil, pero accesoria a la argumentación central. Una digresión suele ser un recurso productivo para profundizar en la explicación o justificación de un tema, apartándose de su tratamiento principal, de modo tal que no se afecte la coherencia del texto. Suele presentarse como un acápite que, aunque integra el texto, se separa formalmente de él mediante una aclaración explícita que con frecuencia se identifica precisamente con el título "Digresión acerca de...". Aunque es un recurso útil para extenderse en una suerte de comentario externo que auxilia a la comprensión del texto, la regla limita su uso sólo a situaciones en las que ello esté plenamente justificado.

2. Cuando la digresión se lleva a una nota de pie de página. Muchos ejemplos hay en la literatura jurídica de este recurso que, al apartarse física y explícitamente del texto principal mediante la llamada (el número en súper índice que identifica la nota), no estorba a la coherencia de este. Una buena forma de resolver las digresiones sin violar la regla de coherencia es, por tanto, enviarlas como notas al pie de página.

Quien ha aducido un argumento está obligado a dar más argumentos en caso de contra argumentos. En este caso la obligación de contra argumentar no es potestativa, sino necesaria para cumplir con el principio de debida diligencia o de exhaustividad de la argumentación que, en este contexto, supone no dejar argumentos sin responder. El proceso de argumentación/contraargumentación garantiza el perfeccionamiento de las razones a través de su depuración: irán quedando fuera las razones que pierden su fundamento y las que son negadas por otras razones más sólidas, de modo que sean éstas últimas las que prevalezcan.

Quien introduce en el discurso una afirmación o manifestación sobre sus opiniones, deseos o necesidades que no se refiera como argumento a una anterior manifestación, tiene que fundamentar porque introdujo esa afirmación o manifestación. Corresponde esta regla a la coherencia lógica del texto, que garantiza la implicación en la cadena de argumentación, sea ésta deductiva (de lo general a lo particular), inductiva (de lo particular a lo general) bien abductiva (de lo particular o a lo particular).

\section{Reglas de fundamentación}

Estas reglas aseguran la lealtad al consenso y las condiciones en las que éste puede desafiarse. 
Quien hace una afirmación con base en una teoría para la satisfacción del interés-de un argumento, debe poder aceptar las consecuencias de dicha teoría también en el caso hipotético de argumentos similares, aplicados a otras situaciones. Aplicada a la investigación jurídica, la regla apela a la honestidad intelectual de quien investiga. Previene que un mismo fundamento, por ejemplo, una teoría jurídica, se aplique de modo diferenciado, según la conveniencia de aquella situación a la que es aplicado.

Las consecuencias de cada regla para la satisfacción de los intereses de cada uno deben poder ser aceptadas por todos. En este caso hay un apelo al consenso en torno a las consecuencias que se siguen de la aplicación de un determinado fundamento o teoría. Puede considerarse como complementaria de la regla anterior.

Toda teoría debe poder estudiarse en forma abierta y general. El consenso no autoriza la censura en torno a posiciones teóricas que puedan resultar novedosas o desafiantes del paradigma dominante. Una investigación jurídica debe poder abrir nuevos campos de estudio.

Las justificaciones que sirven de base a las concepciones teóricas del investigador deben poder pasar la prueba de su génesis histórico-crítica. Una justificación no pasa semejante prueba si:

i. Aunque originariamente se pudiera justificar racionalmente, sin embargo, ha perdido después su justificación. Recurrir a planteamientos teóricos que, habiendo gozado de justificación en el pasado, la han perdido en el contexto contemporáneo, constituye un desafío indebido al consenso actual. Un buen ejemplo lo constituiría el de un investigador que insiste en teorías que avalan la pena de muerte, la prisión perpetua o la readaptación social, en el marco de un estado constitucional de derechos que ya no las justifica.

ii. Si originariamente no se puede justificar racionalmente y no se pueden aducir tampoco nuevas razones que sean suficientes. Este sería el caso de planteamientos teóricos que nunca tuvieron justificación pero que buscan justificarse en nuevas razones sin lograrlo. Un caso así lo constituiría, por ejemplo, el intento por estudiar métodos eugenésicos o de limpieza social e intentar justificarlos racionalmente.

Las justificaciones que sirven de base a las concepciones del hablante deben poder pasar la prueba de su formación histórica individual. Una justificación no pasa semejante prueba si se ha establecido sólo sobre la base de socialización no justificable. No puede haber consenso donde éste ha sido artificialmente manipulado o fomentado.

Hay que respetar los límites de realizabilidad realmente dados. Para el caso que ocupa al presente artículo, esta regla habría que entenderla como la imposición de los límites dentro de los cuales es posible realizar investigación jurídica, es decir, como demarcación científica en sentido concreto, para distinguir aquello que se considera jurídico de lo que excede este campo. En este sentido, el consenso también determina lo que es realizable en tanto ciencia jurídica y lo que no lo es.

En su conjunto, estas reglas permiten evaluar la validez externa de una investigación jurídica, al definir la capacidad de persuasión o generalización como el grado de adecua- 
ción a ellas, en la medida que constituyen criterios de calidad que, en efecto, pueden graduarse -grado de coherencia textual, grado de racionalidad, grado de integridad y grado de lealtad al consenso. Como se ha dicho, no tienen que ver con lo que cada comunidad de investigación considera que es el conocimiento jurídico desde el punto de vista interno o de los contenidos, sino que constituyen una guía metodológica independiente de las distintas aproximaciones jurídicas para la evaluación objetiva de la validez externa de una investigación jurídica, necesidad que, a todas esas aproximaciones, si se pretenden científicas, debería serles común.

Combinada la aplicación de estas reglas con la lógica formal o bien con el modelo de Toulmin, según el tipo de investigación que se esté evaluando, se logra un modelo integral para la determinación de la validez científica de una investigación jurídica.

\section{Reflexiones conclusivas}

A lo largo del texto se ha intentado mostrar que el trabajo académico de las y los juristas puede dar cuenta de su calidad mediante criterios que, más o menos objetivos, identifican el núcleo duro de lo que puede afirmarse como rigor científico, con respeto pleno a la libertad de pensamiento de sus autores. Se trata de controles externos que están destinados a reconocer un procedimiento -sea este formal, material o persuasivo- que guíe la actividad heurística y que exponga la discusión al diálogo, tanto al que tiene el investigador consigo mismo, como el que espera producir con la comunidad de investigación a la que dirige sus aportes. No sobra decir que la propuesta que aquí subyace pretende constituir un modelo de evaluación que pueda ser útil en la dirección y disertación de tesis de pre y posgrado, tanto como en la que se realiza a cargo de pares.

Desde el punto de vista aquí esgrimido, en suma, el método jurídico consistiría entonces en el conjunto de pasos que exigen de la argumentación que subyace a una investigación jurídica, certidumbre o razonabilidad y, en todos los casos, capacidad para generar consenso. Esta es otra aproximación al tema y desde luego, admite por ello una amplia discusión, que queda abierta con las muchas distintas perspectivas desde las que concibe a la investigación jurídica.

\section{Bibliografía}

Alexy, R. (1989), Teoría de la argumentación jurídica, Madrid, Centro de Estudios Constitucionales.

Atienza, M. (2013), Curso de argumentación jurídica, Madrid, Trotta.

Austin (1990), Cómo hacer cosas con las palabras, Barcelona, Paidós.

Ávila Ortiz, R. (2005), "La metodología jurídica en México: un estado del arte, en Cienfuegos, D. Y López Olvera, M.A”. Estudios en homenaje a Don Jorge Fernández Ruiz. México: UNAM/IIJ, pp. 1-28.

Bajtin, M. (1989), Teoría y estética de la novela, Madrid, Taurus.

Boscán, M., y K. Klever (2012), "Metodología basada en el método heurístico de Polya para el aprendizaje de la resolución de problemas matemáticos", Escenarios, vol. 10, núm. 2, julio-diciembre, pp. 7-19. 
Delgado, J.M., y J. Gutiérrez (1999), Métodos y técnicas cualitativas de investigación en ciencias sociales, Madrid, Síntesis.

Fix, H. (1966), "En torno a los problemas de la metodología del derecho", Revista de la Facultad de Derecho de México, núm. 62, [en línea], disponible en: https://revistas-colaboracion.juridicas.unam.mx/index.php/rev-facultad-derecho-mx/article/ view/26306/23685

Habermas, J. (1987), Teoría de la acción comunicativa, 2 v, Madrid, Taurus.

Kahneman, D. (2014), Pensar rápido, pensar despacio, México, Debolsillo.

KRISTEVA, J. (1997), "Bajtin, la palabra, el diálogo y la novela", en Navarro, D. (comp.). Intertextualité. Francia en el origen de un término y el desarrollo de un concepto, La Habana, UNEAC/Casa de las Américas/Embajada de Francia en Cuba.

Kunn, T.S. (2013), La estructura de las revoluciones cientificas, México, FCE.

LARA, L. (1991), Procesos de investigación jurídica, México, IIJ/UNAM.

Martínez Zorrilla, D. (2010), Metodología jurídica y argumentación, Madrid.

Perelman, Ch. y L. Olbrechts-Tyteca (1969), Tratado de argumentación. La nueva retórica, Madrid, Gredos.

Ponce, L. (1996), Metodología del derecho, México, Porrúa.

Sousa Santos, B (2010), Refundación del Estado en América Latina. Perspectivas desde una epistemología del Sur, México, Siglo XXI.

Searle, J.R. (1994), Actos de habla, Buenos Aires, Planeta Agostini

SÁnchez, R. (1997), Metodología de la ciencia del derecho, México, Porrúa.

TAMAYo, R. (1986), El derecho y la ciencia del derecho, México, IIJ/UNAM.

Toulmin, S. (1958), Los usos de la argumentación, Barcelona, Península.

Villoro, M. (1993), Metodología del trabajo jurídico, México, Limusa.

Von Wright, G.H. (1987), Explicación y comprensión, Madrid, Alianza

Witker, J. (1997), Metodología jurídica, México, McGraw Hill.

Wroblezky, J. (2008), Sentido y hecho en el derecho, México, Fontamara. 